\title{
Study protocol of a randomized controlled trial comparing Mindfulness-Based Stress Reduction with treatment as usual in reducing psychological distress in patients with lung cancer and their partners: the MILON study
}

\author{
Melanie PJ Schellekens ${ }^{1 *}$, Desiree GM van den Hurk², Judith B Prins ${ }^{3}$, Johan Molema ${ }^{2}$, A Rogier T Donders ${ }^{4}$, \\ Willem H Woertman ${ }^{4}$, Miep A van der Drift ${ }^{2}$ and Anne EM Speckens ${ }^{1}$
}

\begin{abstract}
Background: Lung cancer is the leading cause of cancer death worldwide and characterized by a poor prognosis. It has a major impact on the psychological wellbeing of patients and their partners. Recently, it has been shown that Mindfulness-Based Stress Reduction (MBSR) is effective in reducing anxiety and depressive symptoms in cancer patients. The generalization of these results is limited since most participants were female patients with breast cancer. Moreover, only one study examined the effectiveness of MBSR in partners of cancer patients. Therefore, in the present trial we study the effectiveness of MBSR versus treatment as usual (TAU) in patients with lung cancer and their partners. Methods/Design: A parallel group, randomized controlled trial is conducted to compare MBSR with TAU. Lung cancer patients who have received or are still under treatment, and their partners are recruited. Assessments will take place at baseline, post intervention and at three-month follow-up. The primary outcome is psychological distress (i.e. anxiety and depressive symptoms). Secondary outcomes are quality of life (only for patients), caregiver appraisal (only for partners), relationship quality and spirituality. In addition, cost-effectiveness ratio (only in patients) and several process variables are assessed.
\end{abstract}

Discussion: This trial will provide information about the clinical and cost-effectiveness of MBSR compared to TAU in patients with lung cancer and their partners.

Trial registration: ClinicalTrials.gov NCT01494883.

Keywords: Mindfulness-based stress reduction, Lung cancer patients, Partners, Psychological distress, Randomized controlled trial

\section{Background}

With an estimated 1.4 million deaths per year, lung cancer is the leading cause of death by cancer worldwide. Even with the best available treatment, five-year survival is merely $16 \%$ and about 60 to $70 \%$ of patients die within the first year after diagnosis [1]. This poor prognosis is often caused by a late diagnosis as the presentation usually

\footnotetext{
*Correspondence: Melanie.Schellekens@radboudumc.nl

'Department of Psychiatry, Radboud University Nijmegen Medical Centre,

Nijmegen, The Netherlands

Full list of author information is available at the end of the article
}

occurs when the lung cancer is advanced. Patients may develop burdensome symptoms like pain, dyspnoea, fatigue and cough and they may undergo radical treatment, including surgery, chemo- and radiotherapy. Not surprisingly, lung cancer has a major impact on the psychological wellbeing of patients and their family. Akechi and colleagues [2] showed that $19 \%$ of patients with advanced lung cancer meets the criteria of psychiatric disorders, especially depressive and adjustment disorders. Of patients who had been successfully treated for lung cancer $15 \%$ met the criteria for a minor or major depressive disorder 
[3]. The prevalence rate of depressive and anxiety symptoms among lung cancer patients ranges from 20 to $47 \%$ [4-7]. Compared to patients with other cancer diagnoses, lung cancer patients report the highest rates of distress $(43$ to $58 \%)[8,9]$ resulting in a lower quality of life [10].

Family, friends and especially partners of patients with lung cancer also have to deal with its psychological impact [11-14]. Partners not only provide emotional and practical support, they also have to cope with their own concerns, including the uncertainty regarding the course of the illness and the fear of losing their partner [15]. More than $50 \%$ of partners of lung cancer patients report negative emotional effects of caregiving [16]. Around 40\% of partners of patients with advanced lung cancer report high levels of distress [17]. The relationship between patient and partner can also be affected by the cancer. It has been shown that some partners report a lower quality of their relationship after the diagnosis of lung cancer [18].

Though numerous studies examined the psychological distress of lung cancer patients and their partners [2-22], not much research is done on how to alleviate distress in these groups [23]. In addition, the available studies on managing the psychosocial care needs of cancer patients and their families have focused on care at the very end of life (e.g. [24-26]). Recently, studies have demonstrated that palliative care initiated early in treatment improves the quality of life and depressive symptoms of lung cancer patients $[10,27]$. This stresses the importance of integrating psychosocial care for lung cancer patients and their partners early in the treatment, rather than instigating it once life-prolonging therapies fail.

In the past ten years MBSR has become a promising psychosocial intervention for cancer patients. Mindfulness is defined as intentionally paying attention to moment-by-moment experiences in a non-judgmental way [28]. MBSR is an 8-week group-based training consisting of meditation practices, such as the bodyscan, gentle yoga, sitting and walking meditation. By repeatedly bringing attention back to the current experience, participants gradually learn to disengage from dysfunctional thoughts and directly experience the emotions and bodily sensations of the present moment. MBSR aims to provide participants with the ability to step back from ruminating about the past or worrying about the future and simply allow experiences to unfold [28,29]. A recent metaanalysis [30] of 13 nonrandomized studies and 9 randomized controlled trials (RCT) concluded there is positive evidence for the use of mindfulness-based interventions in reducing psychological distress in cancer patients. Among the RCT's, a reduction in symptom severity was found for both anxiety and depression corresponding to moderate pooled controlled effect sizes (Hedges's $g=0.37$ and Hedges's $g=0.44$, respectively) [30]. Though mindfulness-based interventions seem to be effective, the authors note that across studies the majority of participants were women (85\%) and diagnosed with breast cancer (77\%). Compared to breast cancer patients, patients with lung cancer are more often male, older and have a poorer prognosis. Furthermore, of these 22 studies only one study included the partners of the patients showing that partners also benefit from the MBSR training [31]. This is quite surprising since partners of cancer patients also report high levels of distress [32].

\section{Aims}

The aim of the Mindfulness for Lung Oncology Nijmegen (MILON) study is to examine the effectiveness of MBSR compared to TAU in reducing psychological distress in patients with lung cancer and their partners. We hypothesize that patients in the MBSR group will report a lower level of psychological distress (i.e. anxiety and depressive symptoms), higher levels of quality of life, quality of relationship and spirituality than those in the TAU group. Medical and societal costs will be lower in the MBSR versus TAU group. We expect partners in the MBSR group to report a lower level of psychological distress and higher levels of caregiver appraisal, relationship quality and spirituality than their counterparts in the TAU group. With regard to the working mechanisms of the MBSR programme, we will examine changes in mindfulness skills, self-compassion, rumination, intrusion, avoidance and adherence to MBSR.

\section{Methods/Design \\ Study design}

The design of the 'MILON' study is a parallel group randomized controlled trial with an embedded process study. Participants are randomized between MBSR and TAU. The study protocol has been approved by our ethical review board (CMO Arnhem-Nijmegen) and registered under number 2011-519.

\section{Participants and procedure}

Patients and partners are recruited at the outpatient clinic of the Department of Pulmonary Diseases, Radboud University Nijmegen Medical Centre (RUNMC) by a nurse practitioner and the attending physician. Patients and partners are invited to participate together but both are welcome to participate on their own if they do not have a partner or their partner is not willing to participate. Patients and/or partners who are interested are provided with an information leaflet. If they are willing to participate, they are invited for a research interview, in which inand exclusion criteria are assessed and informed consent is taken.

At other participating hospitals (Department of Pulmonary Diseases, Canisius-Wilhelmina Hospital, Nijmegen; Department of Pulmonary Medicine, Rijnstate, Arnhem; Department 
of Oncology, Elkerliek Hospital, Helmond; Department of Pulmonary Medicine, Jeroen Bosch Hospital; Department of Pulmonary Diseases, Maas hospital Pantein, Boxmeer) patients and their partners will be sent a letter with the invitation to participate in the study. One week later the researcher calls the patients to answer possible questions and asks whether the patient and partner are interested in participation. If so, they are invited for a research interview at the RUNMC.

\section{Eligibility}

We include patients and/or partners of patients, who are (a) diagnosed with cytologically or histologically proven non-small cell lung cancer or small cell lung cancer and (b) have received or are still under treatment. Exclusion criteria for both patient and partner include: (a) being under 18 years of age, (b) not being able to understand or use the Dutch language, (c) former participation in MBSR or Mindfulness-Based Cognitive Therapy (MBCT), (d) current and regular treatment by psychologist or psychiatrist, (e) current participation in other psychosocial programme and (f) physical or cognitive $(<26$ on the Mini-Mental State Examination (MMSE)) impairments hampering participation in MBSR training or completion of questionnaires.

\section{Baseline}

Patients and partners are interviewed to obtain demographics and clinical characteristics, after which they are screened for cognitive impairments with the MMSE [33]. After that, baseline questionnaires, including the Distress Thermometer (DT) [34,35], are administered, followed by randomization. Table 1 shows the assessment instruments and time points at which the questionnaires are administered to patients and partners.

\section{Randomization}

Randomization is stratified according to setting and minimized for (a) stage of disease (curative versus palliative), (b) baseline level of anxiety and depressive symptoms (anxiety or depression subscale score of Hospital Anxiety and Depression Scale (HADS) $<8$ versus $\geq 8$ ), (c) treatment during MBSR (no treatment versus chemoand/or radiotherapy) and (d) participation (patient alone versus partner alone versus patient and partner together). Randomization is computerized, using a randomization website, specifically designed for this study, on which the researcher can fill out the required data. The researcher communicates treatment allocation to the nurse practitioner, who informs the patient and/or partner.

\section{Follow-up assessments}

Follow-up assessments take place post intervention and at three-month follow-up. Participants who have access to the internet and have an email address receive the questionnaires online. If not, they receive the questionnaires on paper along with a reply envelope. In case of drop-out, the researcher tries to contact the participant by phone to complete a minimum set of outcome measures and to identify the main reason for drop-out.

\section{Intervention}

The MBSR curriculum used is primarily based on the Mindfulness-Based Stress Reduction programme as developed by Kabat-Zinn [28] but contains some elements of the MBCT programme by Segal, Williams and Teasdale [29], like psycho-education on the interrelatedness of feelings and thoughts. Moreover, some modifications have been made to make the intervention more suitable for patients with lung cancer and their partners, such as psycho-education about grief [36]. In addition, a mindful communication exercise in which partners talk with each other about the cancer was added. The programme consists of 8 weekly 2.5 -hour sessions, a silent day between session six and seven and home practice assignments of about 45 minutes, 6 days per week. Participants receive a set of CDs with guided mindfulness meditation exercises for home practice and a folder with information and home practice instructions for the forthcoming week. Table 2 shows the content of the MBSR programme per session. The MBSR courses are taught by mindfulness teachers with extensive training in MBSR. They all fulfil the advanced criteria of the Center for Mindfulness of the University of Massachusetts Medical School [37] and maintain a regular personal meditation practice. Teachers were trained, supervised and assessed to ensure their competency levels met the qualification criteria to instruct the MBSR classes. During the trial, teachers will receive weekly supervision and a number of sessions will be videotaped to evaluate competence and adherence with the Mindfulness-Based Interventions Teaching Assessment Criteria [38].

\section{Outcome measures \\ Primary outcome measure}

Psychological distress The primary outcome measure is the total score on the HADS [39-41], which is developed to measure psychological distress in somatic patient populations. It consists of a 7-item anxiety (HADS-A) and 7-item depression (HADS-D) subscale. The HADS shows good psychometric properties in the general medical population, including oncology patients [42]. Internal consistency as measured with Cronbach's $\alpha$ varied from .84 to $.90[40,42]$. Test-retest reliability was good as Pearson's $r>.80$ were obtained [40,43]. Though the cutoff scores of the HADS vary among populations [44], in lung cancer patients they have found to be $<8$ versus $\geq 8$ on the HADS-A or HADS-D [45]. The HADS has been 
Table 1 Measurements and corresponding time points for patient and partner

\begin{tabular}{|c|c|c|c|c|c|c|c|}
\hline \multirow[t]{2}{*}{ Measure } & \multirow[t]{2}{*}{ Target } & \multicolumn{2}{|c|}{ TO } & \multicolumn{2}{|c|}{ T1 } & \multicolumn{2}{|c|}{ T2 } \\
\hline & & pt & pr & pt & pr & pt & pr \\
\hline MMSE & Cognitive impairments & $x$ & $x$ & & & & \\
\hline DT & General distress & $x$ & $x$ & & & & \\
\hline HADS & Psychological distress & $x$ & $x$ & $x$ & $x$ & $x$ & $x$ \\
\hline QLQ-C30 & Quality of life & $x$ & & $x$ & & $x$ & \\
\hline QLQ-LC13 & Quality of life & $x$ & & $x$ & & $x$ & \\
\hline SIP & Impact of sickness & $x$ & & $x$ & & $x$ & \\
\hline SPPIC & Caregiver burden & & $x$ & & $x$ & & $x$ \\
\hline CRA-SE & Caregiver self-esteem & & $x$ & & $x$ & & $x$ \\
\hline IMS-S & Relationship satisfaction & $x$ & $x$ & $x$ & $x$ & $x$ & $x$ \\
\hline MIS & Communication about cancer & $x$ & $x$ & $x$ & $x$ & $x$ & $x$ \\
\hline SAIL & Spirituality & $x$ & $x$ & $x$ & $x$ & $x$ & $x$ \\
\hline FFMQ & Mindfulness skills & $x$ & $x$ & $x$ & $x$ & $x$ & $x$ \\
\hline SCS & Self-compassion & $x$ & $x$ & $x$ & $x$ & $x$ & $x$ \\
\hline RRS-EXT & Rumination & $x$ & $x$ & $x$ & $x$ & $x$ & $x$ \\
\hline IES & Psychological stress reaction & $x$ & $x$ & $x$ & $x$ & $x$ & $x$ \\
\hline Diary & Health care use, work absence & Mont & stud & & & & \\
\hline Calendar & Mindfulness adherence & Mont & stud & $p l$ dl & & & \\
\hline
\end{tabular}

Note. T0 = Baseline measurement; T1 = Post-intervention measurement; T2= 3-month follow-up measurement; $\mathrm{pt}=$ Patient; $\mathrm{pr}=$ Partner; MMSE = Mini Mental State Examination; DT = Distress Thermometer; HADS = Hospital Anxiety and Depression Scale; QLQ-C30 = Quality of Life - Cancer; QLQ-LC13 = Quality of Life - Lung Cancer; SIP = Sickness Impact Profile; SPPIC = Self-Perceived Pressure from Informal Care; CRA-SE = Caregiver Reaction Assessment - Care-Derived Self-Esteem; IMS-S = Investment Model Scale-Satisfaction; MIS = Mutuality and Interpersonal Sensitivity; SAIL = Spiritual Attitude and Involvement List; FFMQ = Five Facet Mindfulness Questionnaire; SCS = Self-Compassion Scale; RRS-EXT = Rumination Response Scale - Extended Version; IES = Impact of Event Scale.

shown to be highly correlated with the Beck Depression Inventory [42]. It has previously been used in intervention studies of mindfulness and shown to be sensitive to change (e.g. [46]).

\section{Secondary outcome measures}

Quality of life (only for patients) The European Organisation for Research and Treatment of Cancer (EORTC) Core Quality of Life Questionnaire (QLQ-C30) [47] is included, along with the supplemental Lung Cancer questionnaire module (QLQ-LC13) [48]. The QLQ-C30 is designed to use in clinical trials on physical treatments for cancer patients. It incorporates five functional scales (physical, role, cognitive, emotional, social), three symptom scales (fatigue, pain, nausea and vomiting), a global health and quality of life scale and an array of single-item symptom measures. After revisions in the role functioning, global health and physical functioning scale, internal consistency of the subscales varied between .65 and .94 , except for the cognitive functioning scale with $\alpha$ varying from .56 to $.63[47,49,50]$. Test-retest reliability varied from .63 to .86 [51]. The lung cancer questionnaire module is designed to supplement the core questionnaire and comprises specific symptoms associated with lung cancer (coughing, haemoptysis, dyspnoea, pain) and side-effects from conventional chemo- and radiotherapy (hair loss, neuropathy, sore mouth, dysphagia). While the multi-item dyspnoea scale showed high internal consistency, the pain subscale did not. When combined with the dyspnoea and pain items of the core questionnaire, both the dyspnoea $(\alpha=.86)$ and pain $(\alpha=.71)$ subscale showed high internal consistency. Since the QLQ-C30 and QLQ-LC13 are mainly focused on physical symptoms, we added the items Social Interaction and Alertness Behavior of the Sickness Impact Profile (SIP) [52]. Internal consistency was .94 and test-retest reliability was .92 . The SIP correlated with selfassessed sickness and dysfunction [52].

Caregiver appraisal (only for partners) We use the 9item Self-Perceived Pressure from Informal Care (SPPIC) [53] to assess the extent to which caregiving is experienced as burdensome. To also measure positive aspects of caregiving, the 9-item subscale Care-Derived Self-Esteem of the Caregiver Reaction Assessment (CRA-SE) [54] is included. Internal consistency of the SPPIC was .79 and of the CRA-SE was .73. The SPPIC and CRA-SE were unrelated to each other [55].

Relationship quality To measure relationship satisfaction we included the 10-item Satisfaction subscale of the Investment Model Scale (IMS-S) [56]. The IMS-S starts with 5 items that measure concrete examplars of satisfaction, to 
Table 2 Content of MBSR programme per session

\begin{tabular}{|c|c|c|c|}
\hline Theme of session & Meditation exercise & Didactic teaching & Homework \\
\hline \multirow[t]{3}{*}{ 1. Automatic pilot } & \multirow[t]{3}{*}{ - Bodyscan } & - Intention of participating & - Bodyscan \\
\hline & & \multirow[t]{2}{*}{ - Raisin exercise } & - Eating one meal mindfully \\
\hline & & & - Attention for routine activity \\
\hline \multirow[t]{4}{*}{ 2. Mindfulness of the breath } & - Bodyscan & \multirow{4}{*}{$\begin{array}{l}\text { - Imagery exercise to demonstrate } \\
\text { relationship between thoughts } \\
\text { and feelings }\end{array}$} & - Bodyscan \\
\hline & \multirow{3}{*}{$\begin{array}{l}\text { - Sitting mediation with focus } \\
\text { on breath }\end{array}$} & & - Attention for breath \\
\hline & & & - Awareness of pleasant events \\
\hline & & & - Attention for routine activity \\
\hline \multirow[t]{4}{*}{ 3. Observing limits } & - Yoga while lying down & \multirow{4}{*}{$\begin{array}{l}\text { - Seeing exercise to demonstrate } \\
\text { difference between observation } \\
\text { and interpretation }\end{array}$} & - Bodyscan or yoga \\
\hline & \multirow[t]{3}{*}{ - 3-min breathing space } & & - Sitting meditation \\
\hline & & & - Awareness of unpleasant events \\
\hline & & & - 3-min breathing space \\
\hline \multirow[t]{4}{*}{ 4. Opening up to distress } & \multirow{4}{*}{$\begin{array}{l}\text { - Sitting mediation with focus } \\
\text { on breath, body and sound } \\
\text { - 3-min breathing space }\end{array}$} & \multirow{2}{*}{$\begin{array}{l}\text { - Interrelatedness of feelings, } \\
\text { thoughts and bodily sensations }\end{array}$} & - Bodyscan or yoga \\
\hline & & & - Sitting meditation \\
\hline & & \multirow{2}{*}{ - Psychoeducation about grief } & - Awareness of stress reactions \\
\hline & & & - 3-min breathing space \\
\hline \multirow[t]{4}{*}{ 5. Responding to distress } & \multirow{4}{*}{$\begin{array}{l}\text { - Sitting mediation with focus } \\
\text { on breath, body, sound, } \\
\text { thoughts, difficulty } \\
\text { - Walking meditation } \\
\text { - 3-min breathing space }\end{array}$} & - Reacting versus responding & - Meditation by choice \\
\hline & & \multirow[t]{3}{*}{ - Coping with grief } & - Awareness of reaction in difficult situation \\
\hline & & & - Awareness of communication difficulties \\
\hline & & & - 3-min breathing space \\
\hline \multirow[t]{3}{*}{ 6. Mindful communication } & - Yoga in standing position & \multirow{3}{*}{$\begin{array}{l}\text { - Mindful communication exercise } \\
\text { about effect of lung cancer with } \\
\text { their own partner }\end{array}$} & - Sitting meditation or yoga \\
\hline & \multirow[t]{2}{*}{ - 3-min breathing space } & & - Awareness of communication \\
\hline & & & - 3-min breathing space during stress \\
\hline \multirow[t]{2}{*}{ Silent day } & \multicolumn{3}{|l|}{ - Varying meditation exercises } \\
\hline & \multicolumn{2}{|l|}{ - Silent lunch and tea break } & \\
\hline \multirow[t]{4}{*}{ 7. Taking care of yourself } & \multirow{2}{*}{$\begin{array}{l}\text { - Sitting meditation ending in } \\
\text { choiceless awareness }\end{array}$} & \multirow{4}{*}{$\begin{array}{l}\text { - Exercise on taking care of yourself by } \\
\text { examining how to improve balance in life }\end{array}$} & - Meditation without CD \\
\hline & & & - Reflect on training \\
\hline & - Yoga or walking meditation & & \\
\hline & - 3-min breathing space & & \\
\hline \multirow[t]{2}{*}{ 8. The rest of your life } & - Bodyscan & - Reflection on training & - Further sources of information \\
\hline & - Short sitting meditation & - Maintaining practice & \\
\hline
\end{tabular}

enhance the comprehensibility of the global items, which are utilized to form the construct. Internal consistency varied from .79 to .95 and the IMS-S was related to the Dyadic Adjustment Scale. Also, the Mutual Interpersonal Sensitivity scale (MIS) [57] is included to measure communication between partners about the cancer. It contains 18 items and is divided into two scales: open communication and avoiding negative thoughts about the cancer.

Spirituality is measured with the Spiritual Attitude and Involvement List (SAIL) [58] and consists of 26 items, divided into the subscales meaningfulness, trust, acceptance, caring for others, connectedness with nature, transcendent experiences, and spiritual activities. The internal consistency varied from .74 to .88 and test-retest reliability varied from .77 to .92 . All subscales, except for connectedness with nature, were related with the Functional Assessment of Chronic Illness Therapy Spiritual Well-Being Scale.

\section{Costs (only for patients)}

The cost-effectiveness evaluation is carried out from a societal perspective, considering direct as well as indirect health costs. Data on costs are collected prospectively using a diary in which participants register a) health care utilization: the type of care and its duration, and b) cancer-related absence from work. Unit cost estimates are derived from the national manual for cost prices in the health care sector [59]. Costs of reduced ability to work are estimated using the friction costs method, which results in a more realistic estimate than the human capital approach [60]. Treatment costs of MBSR are calculated 
using activity-based-costing methods, thus measuring actual resources (time of therapist, time of patients, facilities) used. All unit cost prices are adjusted to 2013 prices. Unit cost estimates are combined with resource utilization data to obtain a net cost per patient over the entire follow-up period.

\section{Process measures}

Mindfulness skills are examined with the 39-item Five Facet Mindfulness Questionnaire (FFMQ) [61,62]. The FFMQ is based on an exploratory factor analysis of five mindfulness measures, which allowed items from different instruments to form factors, providing an empirical integration of these independent attempts to operationalize mindfulness. This led to the following five subscales: observing, describing, acting with awareness, non-judging of inner experience and non-reactivity to inner experience. Internal consistency varied from .72 to .93 among the different subscales. Most subscales were related to meditation experience, Psychological Well-Being scales and psychological symptoms, including the Brief Symptom Inventory [61]. FFMQ is sensitive to change in mindfulness-based interventions and is found to mediate the relationship between mindfulness practice and improvements in psychological symptoms (e.g. [63]).

Self-compassion is assessed with the Self Compassion Scale (SCS) [64,65], which has 26 items and is divided into six subscales: self-kindness versus self-judgment, common humanity versus isolation, and mindfulness versus overidentification. Internal consistency of the different subscales varied from .75 to .81 and test-retest reliability varied from .80 to .93 . SCS correlated moderately with self-esteem measures, including the Rosenberg Self-Esteem Scale. Furthermore, whereas the self-esteem measures correlated significantly with the Narcissistic Personality Inventory, the SCS was unrelated to narcissism [64]. SCS is sensitive to change through mindfulness-based interventions and is found to mediate MBCT's treatment effects [66].

To measure rumination we administered the extended version of the Ruminative Response Scale (RRSEXT) [67, Raes and Hermans: The revised version of the Dutch Ruminative Response Scale, unpublished instrument]. The RRS-EXT contains 26 items in which a more adaptive thinking style (i.e. reflection) is distinguished from a more maladaptive one (i.e. brooding). Internal consistency varied from .72 to .77 and test-retest reliability varied from .60 to .62 for the brooding and reflection subscales. The concept of rumination seems to be sensitive to change through mindfulness-based interventions and has been shown to mediate the effect of MBSR on depressive symptoms in oncology patients [68].

The psychological stress reaction is measured with the 15-item Impact of Event Scale (IES) [69,70], which assesses two categories of responses: intrusive experiences and avoidance of thoughts and images associated with the event. Internal consistency varied from .65 to .92 [71] and test-retest reliability varied from .79 to .87 among the subscales [69]. IES correlated with anxiety and depression subscales of the General Health Questionaire.

Adherence to MBSR is assessed during the entire study period with a calendar on which participants in the MBSR condition fill out on a daily basis whether they adhere to the mindfulness exercises: either formal practice (e.g. meditation exercise like the bodyscan), informal practice (e.g. activity with awareness) or no exercise. Adherence to MBSR has been shown to mediate the effects of MBCT on depressive symptoms [72].

\section{Statistical analysis plan \\ Sample size}

To determine the required sample size, first the sample size was calculated that would be needed for a simple $t$-test and subsequently it was corrected for clustering, repeated measurements and baseline. A two-sided $t$-test on the total HADS score $[39,40]$ (i.e. our primary outcome measure, examining psychological distress (HADS-total), anxiety symptoms (HADS-A) and depressive symptoms (HADSD)) would require 64 participants in each group to have $80 \%$ power to detect a medium-sized difference (effect size $=0.5)$ with alpha $=0.05$. To correct for clustering, we multiplied this sample size of 64 with the design factor $(1+$ $(n-1) *$ ICC), where $n$ denotes the cluster size and where ICC denotes the intra-cluster correlation. In our study, the treatment groups will consist of 14 people, of whom about 7 will be patients. With $n=7$ and an estimated ICC $=0.01$. [72], the correction factor equals 1.06. To correct for repeated measurements and the use of the baseline measurement as a covariate, we multiplied the required sample size by the design factor $\left((1+\rho) / 2-\rho_{0}^{2}\right)$, where $\rho$ denotes the correlation between the post-treatment HADS measurements, and $\rho_{0}$ denotes the correlation between the baseline HADS with the post-treatment HADS measurements. With $\rho=0.8$ and $\rho=0.5$ as conservative estimates, the second design factor equals 0.65 . Consequently, after correction for clustering and covariates, we arrived at a required sample size of $0.65 * 1.06 * 64=44$ patients per arm. So 88 patients with lung cancer would be required for the study. Based on our pilot study [van den Hurk, Schellekens, Molema, Speckens and van der Drift, in preparation], we expect a $20 \%$ drop-out rate. Therefore, we intend to include 110 patients and 110 partners.

\section{Primary analyses}

The samples of lung cancer patients and partners will be analyzed separately. Baseline characteristics of the 
population will be compared between MBSR and control group to ensure that key variables were evenly distributed by randomization. First, analyses will be based on the intention-to-treat approach. Next, we will perform per-protocol analyses with the treatment-adherent sample (i.e. in the MBSR condition participants have to attend at least four of the eight MBSR sessions [73] and in the TAU condition participants do not attend a mindfulness-based programme).

We will use linear mixed models to analyze all outcome variables (i.e. psychological distress, quality of life (only for patient), caregiver appraisal (only for partner), relationship quality and spirituality), with treatment as fixed factor, baseline measurement as covariate and a random intercept based on MBSR group. This procedure will use all observed data in our analyses. In addition, Cohen's $d$ effect size [74] will be reported based on the difference between the group means on baseline and follow-up scores, divided by the pooled standard deviation at baseline and follow-up.

\section{Secondary analyses}

Cost effectiveness The quality of life measures (i.e. QLQ-C30; QLQ-LC13) will be used to calculate Quality of Adjusted Life Years (QALYs) for each individual. Costs and effects (in terms of QALYs) will be combined in the incremental cost-effectiveness ratio (ICER). The ICER expresses cost-effectiveness in terms of incremental costs per QALY gained. To estimate confidence intervals for the mean of the ICER a non-parametric bootstrapping method will be used, performing 1000 replications of the original data. In order to express the implications of the cost-effectiveness results more clearly, a cost-acceptability curve will be constructed. In case of dominance, a full cost analysis will be conducted to estimate the mean savings per patient per year.

Mediation analyses To examine the possible underlying mechanisms of change in MBSR, mediation analyses will be conducted. Only the data of the treatment-adherent sample will be included in these analyses. By means of a multiple mediation model suggested by Preacher and Hayes [75], we will test the mediating effect of mindfulness skills, self-compassion, rumination and adherence to MBSR on psychological distress, quality of life (only in patients), caregiver appraisal (only in partners), relationship quality and spirituality.

\section{Discussion}

In the last ten years MBSR has not only proven to be a feasible and acceptable intervention in cancer patients [76], but it also seems to be effective in reducing psychological distress [30]. However, the generalization of these results is limited because most participants were female patients with breast cancer. A large part of lung cancer patients already have advanced cancer at time of diagnosis and are confronted with a poor prognosis and low health status. Consequently, they more often report psychological distress than patients with other diagnoses of cancer $[8,9]$. Hence, it is not yet clear whether MBSR is a feasible, acceptable and effective intervention in patients with lung cancer. Moreover, little is known about the effectiveness of MBSR in partners of cancer patients [30], though they also often report psychological distress.

Our pilot study of 19 lung cancer patients and 16 partners participating in an MBSR course, provides preliminary evidence that MBSR is feasible and acceptable in this population (van den Hurk, Schellekens, Molema, Speckens and van der Drift, in preparation). The current trial will answer the question whether MBSR is effective in patients with lung cancer and their partners.

We started enrolment of participants in February 2012. At the moment, we think recruiting a sufficient number of patients and partners will be a challenge due to rapidly fluctuating health status and sudden changes in cancer treatment [77]. The main reasons for declining participation in patients is 'being too ill' or that it is 'too much of a burden during chemo and/or radiotherapy'. Furthermore, no perceived need or motivation for the training is commonly mentioned. Among partners, participation is highly depending on whether the patient is willing to participate. Although partners can take part separately, partners who are interested do often not participate when the patients decline participation.

Considering the difficulty of studying lung cancer patients and their partners [77], our trial will offer valuable information on whether MBSR, as one of the few available psychosocial care programmes, contributes to the alleviation of their psychological distress.

\section{Abbreviations}

MBSR: Mindfulness-based stress reduction; RCT: Randomized controlled trial RUNMC: Radboud University Nijmegen Medical Centre; MBCT: Mindfulnessbased cognitive therapy; MMSE: Mini mental state examination; DT: Distress thermometer; HADS: Hospital anxiety and depression scale; QLQ-C30: Quality of life - cancer; QLQ-LC13: Quality of life - lung cancer; SIP: Sickness impact profile; SPPIC: Self-perceived pressure from informal care; CRA-SE: Caregiver reaction assessment - care-derived self-esteem; IMS-S: Investment model scale-satisfaction; MIS: Mutuality and interpersonal sensitivity; SAIL: Spiritual attitude and involvement list; FFMQ: Five facet mindfulness questionnaire; SCS: Self-compassion scale; RRS-EXT: Rumination response scale - extended version; IES: Impact of event scale.

\section{Competing interests}

The authors declare that they have no competing interests.

\section{Authors' contributions}

All authors contributed to the design of the study. AS, MD and JP are the principal investigators of the study. MS drafted the paper, which was modified and supplemented by all other authors. DH, MS and MD are involved in recruiting participants while MS and DH take care of the logistics of the study and data collection. RD contributed specifically to the statistical analysis plan and WW contributed specifically to the design of the costeffectiveness evaluation. All authors read and approved the final manuscript. 


\section{Acknowledgements}

This research is funded by Foundation Alpe d'HuZes and the Dutch Cancer Society (Grant number KUN 2011-5077, awarded to Prof. dr. Anne E. M. Speckens, Dr. Miep A. van der Drift and Prof. dr. Judith B. Prins).

\section{Author details}

${ }^{1}$ Department of Psychiatry, Radboud University Nijmegen Medical Centre, Nijmegen, The Netherlands. ${ }^{2}$ Department of Pulmonary Diseases, Radboud University Nijmegen Medical Centre, Nijmegen, The Netherlands. ${ }^{3}$ Department of Medical Psychology, Radboud University Nijmegen Medical Centre, Nijmegen, The Netherlands. ${ }^{4}$ Department of Epidemiology, Biostatistics, and Health Technology Assessment, Radboud University Nijmegen Medical Centre, Nijmegen, The Netherlands.

Received: 28 June 2013 Accepted: 19 December 2013 Published: 3 January 2014

\section{References}

1. Jemal A, Bray F, Center MM, Ferlay J, Ward E, Forman D: Global cancer statistics. CA Cancer J Clin 2011, 61(2):69-90.

2. Akechi T, Okamura H, Nishiwaki Y, Uchitomi Y: Psychiatric disorders and associated and predictive factors in patients with unresectable nonsmall cell lung carcinoma: a longitudinal study. Cancer 2001, 92(10):2609-2622.

3. Uchitomi Y, Mikami I, Kugaya A, Akizuki N, Nagai K, Nishiwaki Y, Akechi T, Okamura H: Depression after successful treatment for nonsmall cell lung carcinoma: a 3-month follow-up study. Cancer 2000, 89(5):1172-1179.

4. Montazeri A, Milroy R, Hole D, McEwen J, Gillis CR: Anxiety and depression in patients with lung cancer before and after diagnosis: findings from a population in Glasgow, Scotland. J Epidemiol Community Health 1998, 52(3):203-204.

5. Hyodo I, Eguchi K, Takigawa N, Segawa Y, Hosokawa Y, Kamejima K, Inoue R: Psychological impact of informed consent in hospitalized cancer patients: a sequential study of anxiety and depression using the Hospital Anxiety and Depression scale. Support Care Cancer 1999, 7(6):396-399.

6. Turner NJ, Muers MF, Haward RA, Mulley GP: Psychological distress and concerns of elderly patients treated with palliative radiotherapy for lung cancer. Psychooncology 2007, 16(8):707-713.

7. Hopwood P, Stephens RJ: Depression in patients with lung cancer: prevalence and risk factors derived from quality-of-life data. $J$ Clin Oncol 2000, 18(4):893-903.

8. Zabora J, Brintzenhofeszoc K, Curbow B, Hooker C, Piantadosi S: The prevalence of psychological distress by cancer site. Psychooncology 2001 10(1):19-28

9. Carlson LE, Angen M, Cullum J, Goodey E, Koopmans J, Lamont L, MacRae JH, Martin M, Pelletier $\mathrm{G}$, Robinson J, et al: High levels of untreated distress and fatigue in cancer patients. Br J Cancer 2004, 90(12):2297-2304.

10. Temel JS, Greer JA, Muzikansky A, Gallagher ER, Admane S, Jackson VA, Dahlin CM, Blinderman CD, Jacobsen J, Pirl WF, et al: Early Palliative Care for Patients with Metastatic Non-Small-Cell Lung Cancer. N Engl J Med 2010, 363(8):733-742.

11. Abernethy AD, Chang HT, Seidlitz L, Evinger JS, Duberstein PR: Religious coping and depression among spouses of people with lung cancer. Psychosomatics 2002, 43(6):456-463.

12. Thielemann PA, Conner NE: Social support as a mediator of depression in caregivers of patients with end-stage disease. J Hosp Palliat Nurs 2009, 11(2):82-90.

13. Pinquart $M$, Duberstein PR: Optimism, pessimism, and depressive symptoms in spouses of lung cancer patients. Psychol Health 2005, 20(5):565-578.

14. Kim Y, Duberstein PR, Sorensen S, Larson MR: Levels of depressive symptoms in spouses of people with lung cancer: effects of personality, social support, and caregiving burden. Psychosomatics 2005, 46(2):123-130

15. Mosher CE, Jaynes HA, Hanna N, Ostroff JS: Distressed family caregivers of lung cancer patients: an examination of psychosocial and practical challenges. Support Care Cancer 2013, 21(2):431-437.

16. Mosher CE, Bakas T, Champion VL: Physical health, mental health, and life changes among family caregivers of patients with lung cancer. Oncol Nurs Forum 2013, 40(1):53-61.

17. Ostlund U, Wennman-Larsen A, Persson C, Gustavsson P, Wengstrom Y: Mental health in significant others of patients dying from lung cancer. Psychooncology 2010, 19(1):29-37.
18. Wennman-Larsen A, Persson C, Ostlund U, Wengstrom Y, Gustavsson JP: Development in quality of relationship between the significant other and the lung cancer patient as perceived by the significant other. Eur J Oncol Nurs 2008, 12(5):430-435.

19. Siminoff $L A$, Wilson-Genderson M, Baker $S \mathrm{Jr}$ : Depressive symptoms in lung cancer patients and their family caregivers and the influence of family environment. Psychooncology 2010, 19(12):1285-1293.

20. Manne S, Badr H: Intimacy processes and psychological distress among couples coping with head and neck or lung cancers. Psychooncology 2010, 19(9):941-954.

21. Badr H, Taylor CLC: Effects of relationship maintenance on psychological distress and dyadic adjustment among couples coping with lung cancer. Health Psychol 2008, 27(5):616-627.

22. Buccheri G: Depressive reactions to lung cancer are common and often followed by a poor outcome. Eur Respir J 1998, 11(1):173-178.

23. Walker J, Sawhney A, Hansen CH, Symeonides S, Martin P, Murray G, Sharpe M: Treatment of depression in people with lung cancer: a systematic review. Lung Cancer 2013, 79(1):46-53.

24. Follwell M, Burman D, Le LW, Wakimoto K, Seccareccia D, Bryson J, Rodin G, Zimmermann C: Phase II study of an outpatient palliative care intervention in patients with metastatic cancer. J Clin Oncol 2009, 27(2):206-213.

25. Jordhoy MS, Fayers P, Loge JH, Ahlner-Elmqvist M, Kaasa S: Quality of life in palliative cancer care: results from a cluster randomized trial. J Clin Oncol 2001, 19(18):3884-3894.

26. Gustafson DH, DuBenske LL, Namkoong K, Hawkins R, Chih M-Y, Atwood AK, Johnson R, Bhattacharya A, Carmack CL, Traynor AM, et al: An eHealth system supporting palliative care for patients with non-small cell lung cancer. Cancer 2013, 119(9):1744-1751.

27. Greer JA, Pirl WF, Jackson VA, Muzikansky A, Lennes IT, Heist RS, Gallagher ER, Temel JS: Effect of early palliative care on chemotherapy use and end-of-life care in patients with metastatic non-small-cell lung cancer. J Clin Oncol 2012, 30(4):394-400

28. Kabat-zinn J: Full catastrophe living: using the wisdom of your body and mind to face stress, pain and illness. New York: Delacourt; 1990.

29. Segal ZV, Williams JMG, Teasdale JD: Mindfulness-Based Cognitive Therapy for depression: a new approach to preventing relapse. New York: Guilford Press; 2002.

30. Piet J, Wurtzen H, Zachariae R: The effect of Mindfulness-Based Therapy on symptomps of anxiety and depression in adult cancer patients and survivors: a systematic review and meta-analysis. J Consult Clin Psychol 2012, 80(6):1007-1020.

31. Birnie K, Garland SN, Carlson LE: Psychological benefits for cancer patients and their partners participating in Mindfulness-Based Stress Reduction (MBSR). Psychooncology 2010, 19(9):1004-1009.

32. Hagedoorn M, Sanderman R, Bolks HN, Tuinstra J, Coyne JC: Distress in couples coping with cancer: a meta-analysis and critical review of role and gender effects. Psychol Bull 2008, 134(1):1-30.

33. Folstein MF, Folstein SE, McHugh PR: Mini-mental state: practical method for grading cognitive state of patiens for clinician. J Psychiatr Res 1975, 12(3):189-198.

34. Roth AJ, Kornblith AB, Batel-Copel L, Peabody E, Scher HI, Holland JC: Rapid screening for psychologic distress in men with prostate carcinoma. Cancer 1998, 82(10):1904-1908.

35. Tuinman MA, Gazendam-Donofrio SM, Hoekstra-Weebers JE: Screening and referral for psychosocial distress in oncologic practice. Cancer 2008, 113(4):870-878.

36. Kübler-Ross E: On death and dying. New York: Macmillan; 1969.

37. MBSR teacher certification pathway: complete checklist. http://www. umassmed.edu/uploadedFiles/cfm2/training/MBSR\%20Teacher\% 20Certification\%20Pathway\%20Complete\%20Checklist[1].pdf.

38. Crane RS, Kuyken W, Williams JMG, Hastings RP, Cooper L, Fennell MJV: Competence in teaching mindfulness-based courses: concepts, development and assessment. Mindfulness 2012, 3:76-84.

39. Zigmond AS, Snaith RP: The Hospital Anxiety and Depression Scale. Acta Psychiatr Scand 1983, 67(6):361-370.

40. Spinhoven P, Ormel J, Sloekers PPA, Kempen G, Speckens AEM, VanHemert AM: A validation study of the Hospital Anxiety and Depression Scale (HADS) in different groups of Dutch subjects. Psychol Med 1997, 27(2):363-370.

41. Norton S, Cosco T, Doyle F, Done J, Sacker A: The Hospital Anxiety and Depression Scale: a meta confirmatory factor analysis. J Psychosom Res 2013, 74(1):74-81. 
42. Bjelland I, Dahl AA, Haug TT, Neckelmann D: The validity of the Hospital Anxiety and Depression Scale: an updated literature review. J Psychosom Res 2002, 52(2):69-77.

43. Herrmann C: International experiences with the Hospital Anxiety and Depression Scale: a review of validation data and clinical results. J Psychosom Res 1997, 42(1):17-41.

44. Vodermaier A, Millman R: Accuracy of the Hospital Anxiety and Depression Scale as a screening tool in cancer patients: a systematic review and meta-analysis. Support Care Cancer 2011, 19(12):1899-1908.

45. Castelli L, Binaschi L, Caldera P, Torta R: Depression in lung cancer patients: is the HADS an effective screening tool? Support Care Cancer 2009, 17(8):1129-1132.

46. Branstrom R, Kvillemo P, Brandberg Y, Moskowitz JT: Effects of mindfulness training on psychological well-being and symptoms of stress in cancer patients at 6-month follow-up. Int J Behav Med 2010, 17:306-306.

47. Bjordal K, de Graeff A, Fayers PM, Hammerlid E, van Pottelsberghe C, Curran D, Ahlner-Elmqvist M, Maher EJ, Meyza JW, Brédart A: A 12 country field study of the EORTC QLQ-C30 (version 3.0) and the head and neck cancer specific module (EORTC QLQ-H\&N35) in head and neck patients. EORTC Quality of Life Group. Eur J Cancer 2000, 36(14):1796-1807.

48. Bergman B, Aaronson NK, Ahmedzai S, Kaasa S, Sullivan M: The EORTC QLQ-LC13: a modular supplement to the EORTC core quality of life questionnaire (QLQ-C30) for use in lung cancer clinical trials. Eur J Cancer 1994, 30(5):635-642.

49. Osoba D, Zee B, Pater J, Warr D, Kaizer L, Latreille J: Psychometric properties and responsiveness of the EORTC Quality of Life Questionnaire (QLQ-C30) in patients with breast, ovarian and lung cancer. Qual Life Res 1994, 3(5):353-364

50. Osoba D, Aaronson N, Zee B, Sprangers M, te Velde A: Modification of the EORTC QLQ-C30 (version 2.0) based on content validity and reliability testing in large samples of patients with cancer. Qual Life Res 1997, 6(2):103-108.

51. Hjermstad MJ, Fossa SD, Bjordal K, Kaasa S: Test/retest study of the European Organization for Research and Treatment of Cancer Core Quality of Life Questionnaire. J Clin Oncol 1995, 13:1249-1254.

52. Bergner M, Bobbitt RA, Carter WB, Gilson BS: The Sickness Impact Profile: development and final revision of a health-status measure. Med Care 1981, 19(8):787-805.

53. Pot AM, van Dyck R, Deeg DJH: Ervaren Druk door Informele Zorg: constructie van een schaal [Self-Perceived Pressure from Informal Care: construction of a scale]. Tijdschrift voor Gerontologie en Psychiatrie 1995, 26(5):214-219

54. Given CW, Given B, Stommel M, Collins C, King S, Franklin S: The Caregiver Reaction Assessment (CRA) for caregivers to persons with chronic, physical and mental impairments. Res Nurs Health 1992, 15(4):271-283.

55. Nijboer C, Triemstra M, Tempelaar R, Sanderman R, van den Bos GAM: Measuring both negative and positive reactions to giving care to cancer patients: psychometric qualities of the Caregiver Reaction Assessment (CRA). Soc Sci Med 1999, 48:1259-1269.

56. Rusbult CE, Martz JM, Agnew CR: The Investment Model Scale: measuring commitment level, satisfaction level, quality of alternatives, and investment size. Pers Relat 1998, 5(4):357-391.

57. Lewis FM, Fletcher KA, Cochrane BB, Fann JR: Predictors of depressed mood in spouses of women with breast cancer. J Clin Oncol 2008, 26(8):1289-1295.

58. de Jager-Meezenbroek E, van den Berg M, Tuytel G, Visser A, Garssen B: Het meten van spiritualiteit als een universeel fenomeen: de ontwikkeling van de Spirituele Attitude en Interesse Lijst (SAIL) [Measuring spirituality as a universal human experience: the development of the Spiritual Attitude and Involvement List (SAIL)]. Psychosociale Oncologie 2006, 14(3):14-15.

59. Hakkaart- van Roijen L, Tan SS, Bouwmans CAM: Handleiding voor kostenonderzoek: methoden en standaard kostprijzen voor economische evaluaties in de gezondheidszorg. [Manual for cost research: methods and unit-prices for economic evaluations in health care]. Diemen: College voor Zorgverzekeringen; 2010 [actualized version].

60. Koopmanschap MA, Rutten FFH, van Ineveld BM, van Roijen L: The friction cost method for measuring indirect costs of disease. J Health Econ 1995, 14(2):171-189.

61. Baer RA, Smith GT, Lykins E, Button D, Krietemeyer J, Sauer S, Walsh E, Duggan D, Williams JMG: Construct validity of the Five Facet Mindfulness
Questionnaire in meditating and nonmeditating samples. Assessment 2008, 15(3):329-342.

62. Veehof MM, ten Klooster PM, Taal E, Westerhof GJ, Bohlmeijer ET: Psychometric properties of the Dutch Five Facet Mindfulness Questionnaire (FFMQ) in patients with fibromyalgia. Clin Rheumatol 2011, 30(8):1045-1054.

63. Carmody J, Baer RA: Relationships between mindfulness practice and levels of mindfulness, medical and psychological symptoms and well-being in a Mindfulness-Based Stress Reduction program. J Behav Med 2008, 31(1):23-33

64. Neff KD: The development and validation of a scale to measure self-compassion. Self Identity 2003, 2(3):223-250.

65. Neff KD, Vonk R: Self-compassion versus global self-esteem: two different ways of relating to oneself. J Pers 2009, 77(1):23-50.

66. Kuyken W, Watkins E, Holden E, White K, Taylor RS, Byford S, Evans A, Radford S, Teasdale JD, Dalgleish T: How does Mindfulness-Based Cognitive Therapy work? Behav Res Ther 2010, 48(11):1105-1112.

67. Treynor W, Gonzalez R, Nolen-Hoeksema S: Rumination reconsidered: a psychometric analysis. Cogn Ther Res 2003, 27(3):247-259.

68. Labelle LE, Campbell TS, Carlson LE: Mindfulness-Based Stress Reduction in oncology: evaluating mindfulness and rumination as mediators of change in depressive symptoms. Mindfulness 2010, 1:28-40.

69. Horowitz M, Wilner N, Alvarez W: Impact of Event Scale: measure of subjective stress. Psychosom Med 1979, 41(3):209-218.

70. Brom D, Kleber RJ: De Schok Verwerkings Lijst [The Impact of Event Scale]. Ned Tijdschr Psychol 1985, 40:164-168.

71. Sundin EC, Horowitz MJ: Impact of Event Scale: psychometric properties. Br J Psychiatry 2002, 180:205-209.

72. van Aalderen JR, Donders ART, Giommi F, Spinhoven P, Barendregt HP, Speckens AEM: The efficacy of Mindfulness-Based Cognitive Therapy in recurrent depressed patients with and without a current depressive episode: a randomized controlled trial. Psychol Med 2012, 42(05):989-1001.

73. Teasdale JD, Segal ZV, Williams JMG, Ridgeway VA, Soulsby JM, Lau MA: Prevention of relapse/recurrence in major depression by mindfulness-based cognitive therapy. J Consult Clin Psychol 2000, 68(4):615-623.

74. Cohen J: Statistical power analysis for the behavioral sciences. 2nd edition. Hillsdale: L. Erlbaum; 1988.

75. Preacher KJ, Hayes AF: Asymptotic and resampling strategies for assessing and comparing indirect effects in multiple mediator models. Behav Res Methods 2008, 40(3):879-891.

76. Würtzen $H$, Dalton SO, Andersen KK, Elsass P, Flyger $H$, Sumbundu A Johansen C: Who participates in a randomized trial of Mindfulness-Based Stress Reduction (MBSR) after breast cancer? A study of factors associated with enrollment among Danish breast cancer patients. Psychooncology 2012, 22(5):1180-1185.

77. Schofield P, Ugalde A, Carey M, Mileshkin L, Duffy M, Ball D, Aranda SK: Lung cancer: challenges and solutions for supportive care intervention research. Palliat Support Care 2008, 6:281-287.

doi:10.1186/1471-2407-14-3

Cite this article as: Schellekens et al:: Study protocol of a randomized controlled trial comparing Mindfulness-Based Stress Reduction with treatment as usual in reducing psychological distress in patients with lung cancer and their partners: the MILON study. BMC Cancer 2014 14:3.

\section{Submit your next manuscript to BioMed Central and take full advantage of:}

- Convenient online submission

- Thorough peer review

- No space constraints or color figure charges

- Immediate publication on acceptance

- Inclusion in PubMed, CAS, Scopus and Google Scholar

- Research which is freely available for redistribution 